\title{
Carne, queda e vôo: a Divina Comédia de Paulo Gaiad
}

\author{
Flesh, fall and flight: Paulo Gaiad's Divine Comedy
}

por Priscilla Menezes de Faria

\section{RESUMO}

Investigação acerca das noções de queda e vôo, como movimentos narrativos, na obra Divina Comédia de Paulo Gaiad. A partir de algumas semelhanças poéticas, relaciona-se a obra de Gaiad com a Divina Comédia de Dante Alighieri e Nadja de André Breton e, através destas relações, busca-se compreender algumas singularidades da obra de Gaiad. TrabaIhando com os conceitos de sedução em Baudrillard, de carne em Bataille e a imagem da esfinge proposta por Moraes; compreende-se que, enquanto, em Dante, o corpo empreende um vôo partindo do inferno em direção ao céu e em Nadja o corpo errante da narrativa surrelista se projeta em queda na direção de ambientes infernais, na Divina Comédia de Gaiad cair e voar coincidem e se tornam movimentos indistintos a partir de um corpo em êxtase para o qual perdição e salvação se dão como um mesmo destino.

Palavras-chave Paulo Gaiad; Divina Comédia; Narrativa

\section{ABSTRACT}

Research about falling and flying as narrative movements in Paulo Gaiad's work Divine Comedy. Because of some poetic similarities, we relate Gaiad's work with Dante Alighieri's Divine Comedy and André Breton's novel Nadja and through this relations we seek some singularities in Gaiad's work. Working with Baudrillard's concept of seduction, Bataille's concept of flesh and the image of the Sphinx proposed by Moraes, we understand that, while in Dante's text the body flies from the hell to the skies and while in Nadja the wandering surrealist body is projected towards hell's environments, in Gaiad's Divine Comedy falling and flying are coincident moviments of a body for wich destruction and salvation become a single destination.

Keywords Paulo Gaiad, Divine Comedy; Narrative 
Paulo Gaiad é natural de Piracicaba, São Paulo. Arquiteto formado em Brasília, em 1981 se instalou em Florianópolis e, já residindo na Ilha, assumiu a prática artística como seu principal ofício. Entre pinturas, desenhos, escritos, objetos escultóricos e experimentações audio-visuais, figura Divina Comédia, obra desenvolvida entre 2003 e 2007 pelo artista. Trata-se de uma série dividida em três partes - Inferno, Purgatório, Paraíso - assim como o texto homônimo de Dante Alighieri. 0 artista relata ter tido contato, ainda criança, como uma edição da obra de Dante ilustrada por Gustave Doré. Ao fascínio que essas imagens Ihe causaram na ocasião, Gaiad relaciona o de desejo de criar ele mesmo um imaginário relacionado à Divina Comédia.

\section{Guias desviantes}

No Inferno criado por Gaiad, comparecem imagens de guerra e violência apropriadas pelo artista, posteriormente envoltas em arame e perfurada por pregos. 0 Paraíso é constituído de mais de 80 imagens, detalhes de um livro de fotografias eróticas do século XIX, coladas sobre chapas de gesso, quebradas, novamente reparadas e então lixadas de forma a adquirirem aparência rasurada e desgastada. Por fim, o Purgatório se trata de uma coleção de fotografias pertencentes a uma família desconhecida e adquiridas em uma feira de antiguidades, impressas em papel jornal e trabalhadas sobre fundo de papelão.
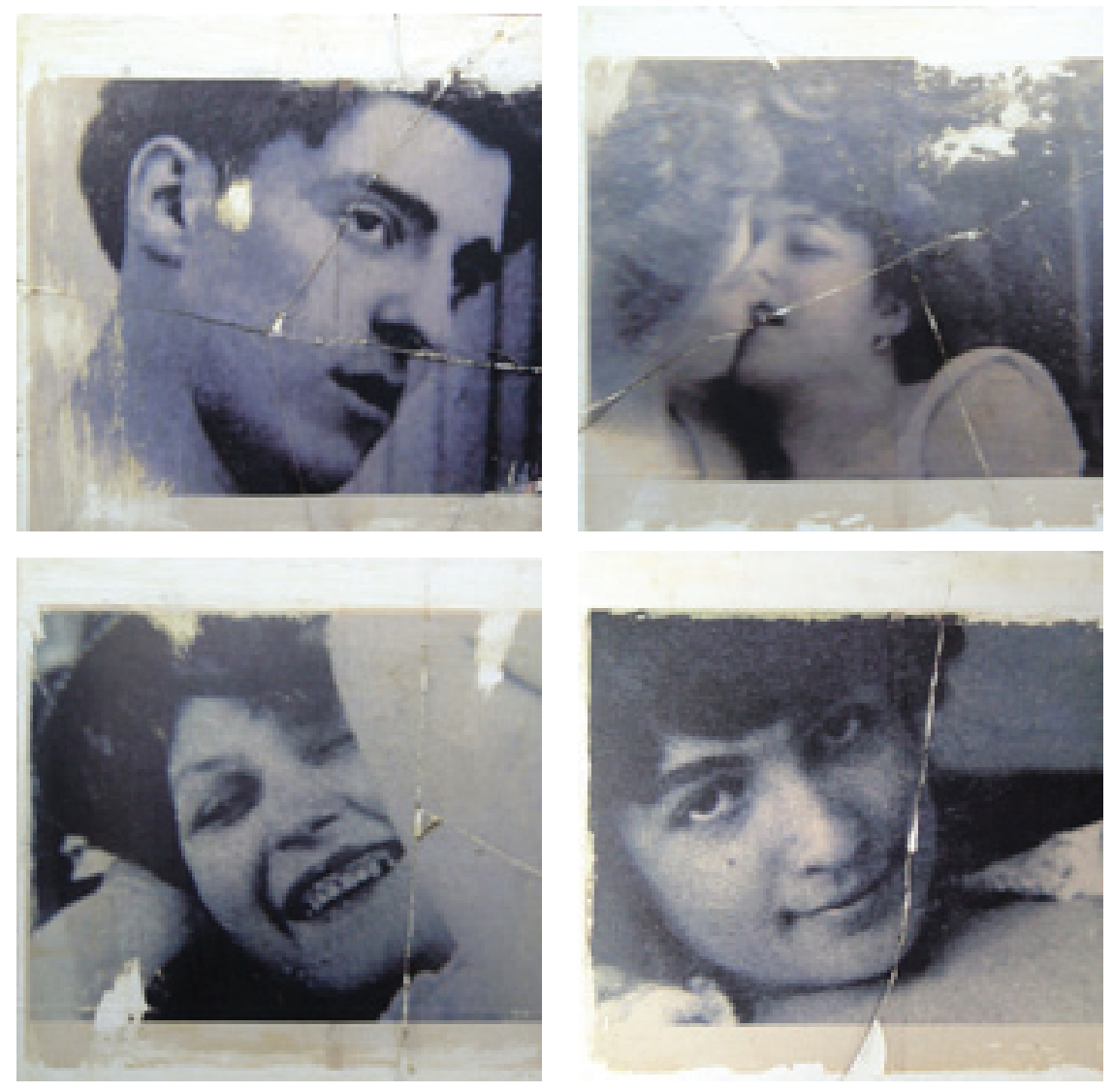

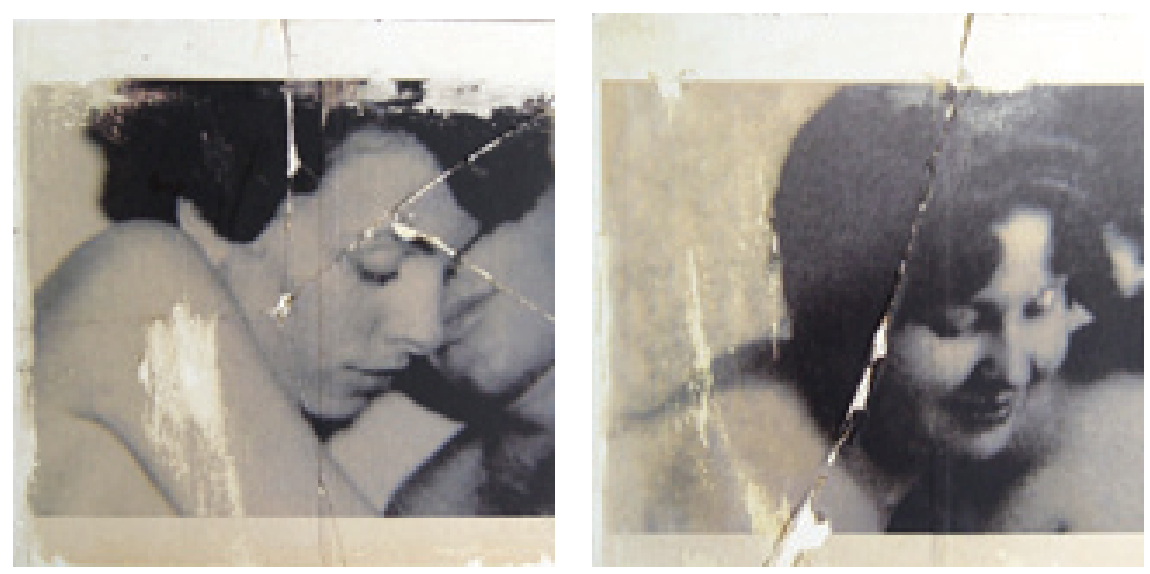

Imagens de Paraíso, parte da série Divina Comédia - Paulo Gaiad Fotografia sobre placas de gesso (2003- 2007)

Fato marcante deste trabalho é a persistência do elemento corpóreo em todos os espaços criados. No inferno, o corpo é violado, amarrado, perfurado, velado, massificado, rasgado, acuado e assassinado. As imagens de guerra são potencializadas pelas intervenções feitas com obejtos cortantes e metálicos em suas superfícies. No paraíso, o corpo goza - sorri, olha, toca, é tocado. Entretanto, as imagens do paraíso são fragmentárias, parte do corpo é sempre obliterada, velada. São imagens de lampejos, instantes inapreensíveis, como é o próprio gozo, a própria paixão. Também o gesso quebrado que thes serve de suporte é a materialização desta fragilidade do ambiente paradisíaco. Se a maioria das imagens do Inferno parecem dotadas de um peso histórico e advir de situações de violência pública e coletiva, como são as guerras, o Paraíso parece particular, íntimo e, neste sentido, quase impenetrável. Já os corpos do purgatório parecem pouco dotados de fortes paixões, olhares apáticos, céticos, calmos e contemplativos nos são dirigidos pelos anônimos retratados. Entre imagens domésticas e comuns, os corpos do purgatório são banais e ordinários como os suportes de papelão sobre o quais estão afixados. Nada de extraodinário sentir parece ser a purga destes corpos que aguardam pelo seus destinos.
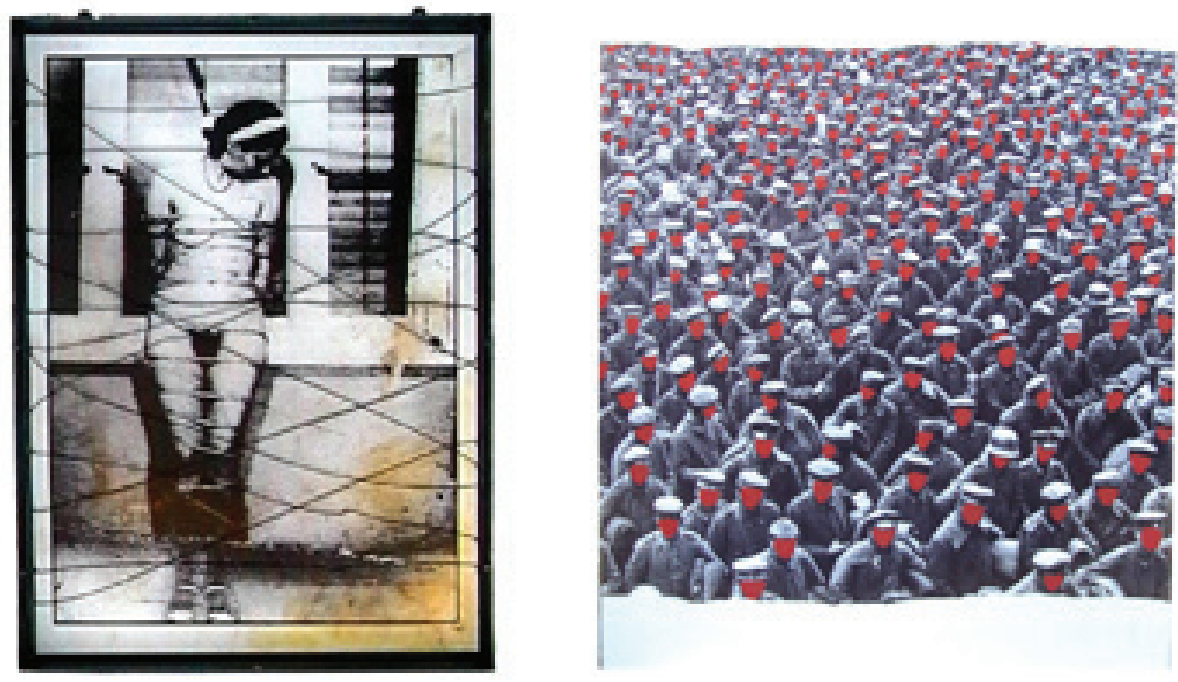

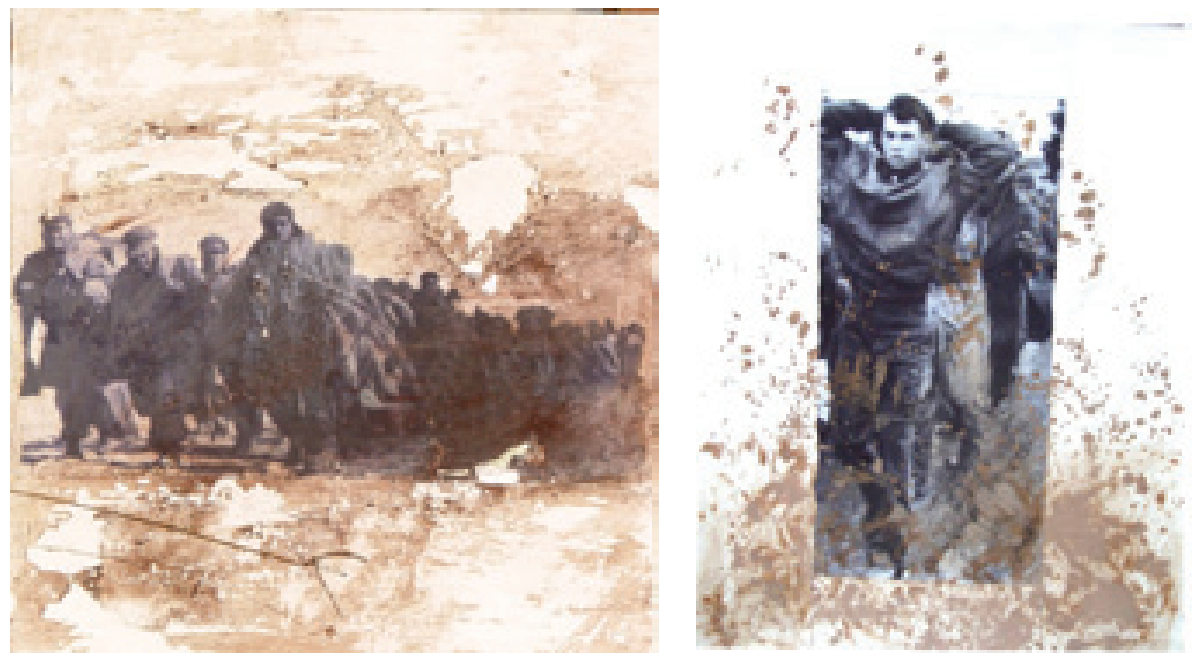

Imagens de Inferno, parte da série Divina Comédia - Paulo Gaiad

Fotografia sobre papel jornal com intervenções do artista (2003- 2007)

Todas as imagens desta série possuem um aspecto envelhecido, o que thes colocam em uma dimensão fronteiriça entre a memória e o esquecimento. 0 fato de terem sido apropriadas de locais quase irrecuperáveis também lhes atribui essa aura de um passado presente, ausência presentificada, fantasma que retorna. Os corpos retratados que comparecem na Divina Comédia erram, na fantasmagoria desse percurso imemorial entre esses três cenários de um suposto destino final. Esse trajeto se dá, na obra de Gaiad, pela noção de série, onde somos convidados a nos deslocarmos, junto dos retratados, por cada um dos cenários criados.
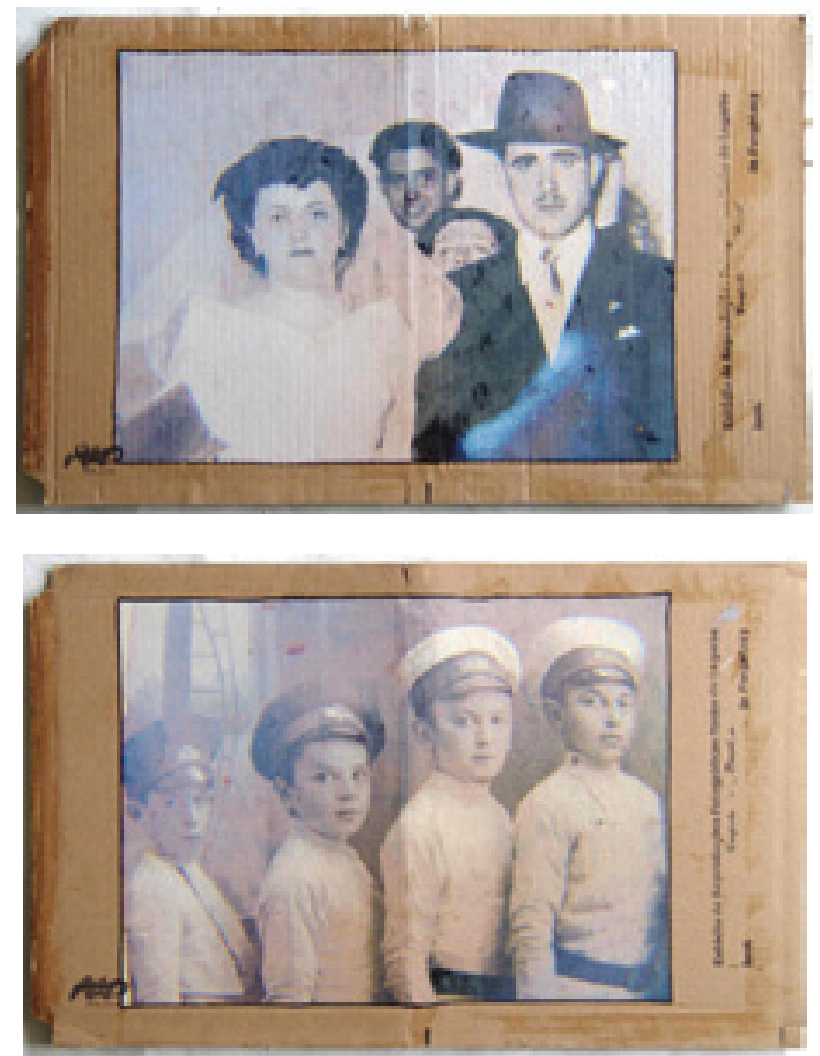

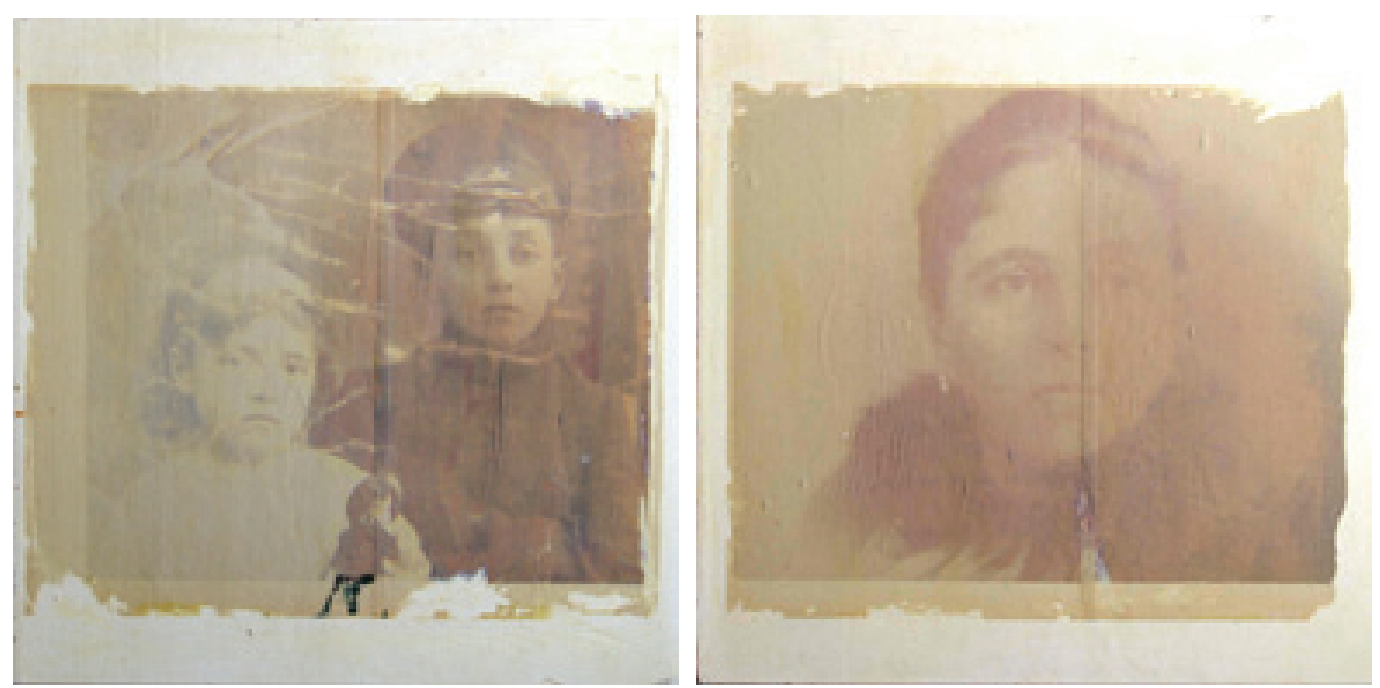

Imagens de Purgatório, parte da série Divina Comédia - Paulo Gaiad Fotografia sobre papelão (2003- 2007)

Na obra de Dante o trajeto se inicia pelo Inferno, passa pelo Purgatório e termina no Paraíso - por isso a nomenclatura comédia, já que, ao contrário da tragédia, o fim é feliz e sublime. Nesse trajeto existem elementos que interessam para pensarmos esta obra de Gaiad. 0 primeiro deles é o fato de todo o percurso de Dante ser acompanhado por um guia, no Inferno e no Purgatório quem Ihe acompanha é o poeta romano Virgílio, que apesar de ser descrito como uma alma boa, viveu antes de Cristo (entre 70 e 19 a.C) e, portanto, não foi batizado, tornando-se após a morte um habitante do limbo. Virgílio, sendo chamado "mestre", conduz o poeta às portas do Paraíso, onde já não poderia entrar. Desse ponto em diante, até Deus, é a sua eterna amada Beatriz que guiará o poeta.

Baudrillard ressalta a raiz etmológica do verbo seduzir: se-ducere, afastar, desviar de seu caminho (1991, p.28). Pensada como uma forma de estratégia de deslocamento, seduz aquele que conduz, que leva, que guia até destinos desviantes. No texto de Dante há uma dupla relação com o seus guias, se estes the conduzem a um destino desejado - a presença divina - é preciso desviar, errar, cruzar todos os círculos infernais e todos os céus paradisíacos antes de chegar a Deus. A sedução, neste caso, está no trajeto que se percorre, na necessidade de incorrer por toda a arquitetura infernal e celestial como meio de chegar ao absoluto. Fato é que o texto de Dante narra meticulosamente a travessia até o paraíso e encerra justo no ponto em que o poeta atinge a luz divina.

Daqui por diante, mais omisso será o meu narrar e mais confuso o meu dizer do que o balbuciar de infante que tem os lábios presos ao seio maternal. (...) Oh! Como é pobre a expressão humana para descrever o que vi! Toda ela, a mais alta, não bastaria para reproduzir o mínimo que eu pretendesse referir. ó lume eterno, que em ti próprio tens sede, só tu a ti mesmo entendes e por ti és entendido, e amas e te comprazes nesse entendimento! (...) Neste ponto faltou alento à minha inspiração. Mas já, 
então, Deus dominava minha vontade, fazendo-a conforme ao seu amor, qual roda obediente ao mando do motor-amor que move o sol e as estrelas. (p.335)

Do encontro com o divino, pouco se pode dizer, é o percurso errante que interessa à narrativa. Por isso, pode-se considerar o trajeto narrativo do poeta como uma forma de desvio e assim, seus guias, como elementos sedutores - encaminham desviando, levam afastando. Levam o poeta até o ponto indizível, o que uma é forma de descaminho, pois encaminham o poeta até lá onde ele nada mais pode cantar. No trabalho de Gaiad quem parece servir como guia entre os espaços é a recorrência da imagem corpórea que incide e retorna. Seduzem, porque tampouco se esclarecem, se desvendam. Afirmam a si mesmos, justo no ponto em que nada de si podem revelar. Apenas indicam, apontam e desviam. Baudrillard ainda diz que a sedução está muito próxima da ideia de fragilidade, e distante da noção de produção.

Seduzir é fragilizar. Seduzir é desfalecer. É através da nossa fragilidade que seduzimos, jamais por poderes ou signos fortes. É essa fragilidade que pomos em jogo na sedução, e é isso que lhe confere seu poder. Seduzimos por nossa morte, por nossa vulnerabilidade, pelo vazio que nos persegue. (1991, p.94)

Assim seduzem as imagens de Divina Comédia de Paulo Gaiad, pelo apagamento, pela efemeridade, pela fantasmagoria, pelo desfalecimento dos corpos. E esta sedução guia aquele que olha a obra rumo à perda de si pelos nos espaços paradisíacos e infernais. As imagens do guia e a noção de sedução tem a ver com os movimentos de queda e vôo que se busca investigar nesta série da Divina Comédia, já que o corpo que empreende esse trajeto entre o inferno e o paraíso, pode estar tanto caindo rumo aos subssolos infernais, como ascendendo ao paraíso. $\mathrm{E}$ esse movimento que desestabiliza o corpo e o faz mergulhar em alguma alguma profundidade é impulsionado por esse sentido de atração. Na obra de Dante, o poeta empreende um vôo, rumo ao lume divino. Quem guia seu vôo final é Beatriz, a intrigante figura que permeia toda a obra de Dante.

\section{Esfinge}

Em um livro menos conhecido de Dante Alighieri, anterior à Divina Comédia, intitulado Vida nova e escrito por volta de 1294, o poeta reúne sonetos e canções uma balada nos quais se apresenta como um poeta saindo da juventude sob o impacto da morte de sua amada, Beatriz. A história desse amor é contada sem oferecer nomes de pessoas e lugares, no texto, apenas Beatriz é nomeada. Especula-se que este nome possa ser um apelido: Beatriz como aquela que dá beatitude. Neste texto narra seu primeiro encontro com Beatriz ainda criança, ocasião em 
que já se sente acometido por grande amor, seus poucos e distantes encontros até a narrativa morte prematura da amada. A partir da morte de Beatriz, Dante passa a peregrinar poeticamente em direção à amada. 0 amor por Beatriz passa a ser o próprio amor divino. Na Divina Comédia de Dante, Beatriz é a única que pode lhe guiar até a luz de Deus. Assim, o amor que jamais foi consumado é o amor da eleveção, dos movimentos ascendentes e de vôos em direção ao espaço paradisíaco. Alguns leitores de Dante levantam a hipótese de a verdadeira Beatriz sequer ter existido e funcionar, na obra do autor, como essa pura imagem intagível, tocada somente no espaço poético. Fato é que pouco importa, para esta pesquisa, verificar a plausibilidade da real existência de Beatriz, já que a imagem da amada morta, perdida antes de ter sido tocada, como a imagem daquela que seduz em direções ascendentes, é potente por si mesma. Beatriz é perda, Paraíso é perda, ambos são imagens desse amor imenso, diante do qual a linguagem se vê debilitada. Baudrillard escreve

Ora, a mulher nada mais é que aparência. E é o feminino como aparência que põe em xeque a profundidade do masculino. (...) Não é exatamente o feminino como superfície que se opõe ao masculino como profundidade; é o feminino como indistinção da superfície e da profundidade. (1991, p.15)

Assim é a feminilidade-Beatriz: inefável e profunda a um só tempo. Impressão na qual se mergulha, aparência em que se perde. De maneira aproximada, as imagens fotográficas da Divina Comédia de Gaiad também guardam a potência da aparência que é profundidade, a um só tempo promessa de absoluto e rasgo sempre incompleto. Hiperestéticos ou apáticos, gozosos ou torturados, os corpos da série de Gaiad se apresentam na plena potência de suas imperativas desaparições. Baudrillard diz ainda

(...) o feminino está em outro lugar, sempre esteve em outro lugar: é esse o segredo de seu poder. Assim como se diz que uma coisa dura porque sua existência é inadequada à sua essência, é preciso dizer que o feminino seduz porque nunca está onde pensar estar. (1991, p.11)

Beatriz, personificação desse feminino sedutor e ausente, guia das direções arrebatadoras, dos excessos intratáveis da linguagem, se aproxima muito de uma sensibilidade surrealista acerca das mulheres. Perigosas porque muito aproximadas à loucura e, justamente por isso, fascinantes aos surrealistas, as mulheres foram tratadas como esse elemento descentrado e imprevisível. Exemplo desta noção de feminilidade no surrealismo é o romance Nadja de André Breton. Publicado em 1928, o romance é uma trama entre narrativa biográfica, contato entre palavra e imagem e uma radical experiência da linguagem, além do relato de um sujeito apaixonado. Assim como Dante, Breton é o narrador-personagem do texto e empreende a sua própria peregrinação: em vez dos círculos infernais, percorre as ruas de Paris em busca de Nadja. Entre encontros ocasionais e planejados, Breton cria e narra sua Nadja. Ela está nos sonhos de Breton, nas ruas de Paris, em toda parte e em lugar nenhum. A narrativa é onírica e inconsciente, mas faz uso 
de fotos de lugares existentes em Paris, de forma a confundir o registro ficcional com o documental. 0 fim de Nadja é próximo ao de Beatriz, ambas perdem-se nos limites além da linguagem. Se Beatriz incursiona no lume divino com seu amado, Nadja enlouquece completamente e é internada no hospício de Vaucluse. Ambas as musas erráticas, potencializam a exploração dos pontos de contato entre a vida e o sonho, entre a estrutura e a desmedida. Nadja e Beatriz percorrem arquiteturas: as ruas de Paris evocadas por Breton e a arquitetura dos espaços infernais e paradisíacos bem construída e explicitada por Dante; mas, percorrendo a estrutura, levam ao desvario, ao imprevisto, ao ponto em que a linguagem não acompanha.

Eliane Robert Moraes, no prefácio da edição de 2007 de Nadja, propõe a figura da mulher que guia o narrador como uma espécie de esfinge, criatura mitológica, originária do antigo Egito, dotada de rosto de pessoa e corpo de leão. Também parte da mitologia e literatura grega, a esfinge é narrada como propositora de enigmas mortais, capazes de salvar ou destruir vidas. Decifra-me ou devoro-te, propõe a Esfinge àquele que deseja passar por ela, enigma e vida, assim, estão completamente tramados. A respeito de Nadja como uma face da esfinge, Moraes escreve:

Livre das referências tradicionais, a nova esfinge será encontrada nos lugares mais prosaicos da cidade, sempre em sintonia com a dinâmica transitória da vida cosmopolita. Errante e provisória, ela vai ostentar vários rostos para, então, revelar múltiplas faces do enigma. (2007, p.9)

Se os rostos e identidades dos corpos fotografados que comparecem na Divina Comédia de Gaiad são obliterados pelo esquecimento e o anonimato, Nadja, apesar de ser personagem de um romance todo entremeado de fotografias, não tem suas feições reveladas. São corpos do puro movimento e da breve apreensão. Moraes afirma:

Entende-se porque, justo num livro em que a fotografia é tão importante quanto o texto não haja uma só imagem a identificar os traços de sua heroína: portadora de uma interrogação, Nadja não se pode confinar nos contornos de um rosto. Melhor dizendo, o que se mostra nela é precisamente o mistério (...). (2007, p.12)

Parafraseando a última frase do romance Nadja, a famigerada máxima surrealista: a beleza será convulsiva, ou não será, Marx Ernst escreve: a identidade será convulsiva ou não será. De beleza e identidade convulsas, Nadja é esfinge que devora pela ausência de um enigma enunciado. De maneira semelhante, os rostos anônimos da Divina Comédia de Gaiad atuam como esfinges silenciosas, que se mostram e nos olham, parecendo nos fazer a pergunta que é a primeira frase do romance de Breton: Quem sou? A potência dos corpos-esfinge de Gaiad, neste sentido, parece a constante repetição do enigma, que não poderá ser resolvido, numa lógica em que ser devorado pela Esfinge - afetado pela obra - é a única maneira de decifrá-la. 


\section{Queda em vôo}

Pode-se supor que o movimento de Dante com Beatriz seria um vôo e o de Breton com Nadja uma queda. Estas suposições fazem sentido se colocarmos em contraposição a sensibilidade medieval e a sensibilidade surrealista. A salvação era, para o homem medieval, destino não apenas desejável como bastante possível para todo aquele que seguisse os preceitos cristãos. 0 caminho do homem medieval, em vida, é assemelhado ao caminho de Dante - do inferno à redenção, já que, para o homem medievo as provações terrenas seriam desejáveis e favoráveis para o ingresso no paraíso após a morte. Assim, o vôo em direção às altitudes celestiais, era uma possibilidade bastante palusível para um homem desta época. Já a noção de salvação para um surrealista estaria desacreditada e em falência, já que, tendo superado os grandes projetos Iluministas europeus, o surrealista não tem nem Deus, nem o Estado e nem o Sujeito como vias de salvação do ser, restando-lhe apostar no sonho, no inconsciente, na desmedida. Assim, o trajeto de Nadja é em direção à loucura, ao desvario de toda razão. Os espaços infernais, neste sentido, são mais aceitáveis e, mesmo, desejáveis a uma sensibilidade surrealista. Ainda quem guardem suas nuances e singularidades, estas duas obras apresentam, em linhas gerais, movimentos distintos de salvação e perdição.

Na Divina Comédia de Gaiad, um movimento é suspeitado - do paraíso ao inferno ou do inferno ao paraíso - pela própria noção de série e pela referência direta à obra de Dante, entretanto não se consegue advinhar se a narrativa imagética é uma queda em direção ao inferno ou uma subida em direção ao paraíso. Não são distintos ascender e o cair, prazer e dor, documental e ficcional, paradisíaco e infernal, porque é possível que na Divina Comédia de Gaiad queda e vôo sejam movimentos coincidentes.

o corpo como elemento comum a todos os cenários da série de Paulo Gaiad pode ser o responsável por essa premeditada coincidência entre cair e ascender. Bataille escreve

0 que 0 ato de amor e o sacrifício revelam é a carne. 0 sacrifício substitui pela convulsão cega dos órgãos a vida ordenada do animal. 0 mesmo acontece com a convulsão erótica: ela libera órgão pletóricos num jogo cego que suplanta a vontade ponderada dos amantes. A essa vontade ponderada sucedem os movimentos animais desses órgãos cheios de sangue. Uma violência que escapa ao controle da razão anima esses órgãos, distende-os até o limite máximo e, de repente, é a felicidade máxima que s se atinge ao ultrapassar essa desordem. 0 movimento da carne excede um limite na ausência da vontade. A carne é em nós esse excesso que se opõe à lei da decência. A carne é o inimigo que nasce dos que são possuídos pelo interdito cristão. Mas se, como eu creio, existe um interdito vago e global que se opõe à liberdade sexual sob formas dependentes dos tempos e lugares, a carne é a expressão de uma volta dessa liberdade ameaçadora. (1987, p.86) 
Corpo que sente - carne - é o elemento que pode ser levado aos extremos, gozo e dor, paraíso e inferno. Essa parece ser a potência dos corpos que se apresentam em a Divina Comédia de Paulo Gaiad. Conforme a compreensão bataillana esses extremos, o abissal e o elevado, de muitas maneiras podem coincidir. 0 êxtase, esse estado que desliza dos domínios da linguagem, parece ser o próprio local da coincidência entre paraíso e inferno. Somente o purgatório, o meio-termo, a apática espera, é o local do corpo indiferente na obra. Esses movimentos impulsionadores em direção aos extremos da paixão são, neste sentido são ao mesmo tempo movimentos de subir e descer, ganhar e perder, salvar-se e perder-se. Há uma passagem da Divina Comédia de Dante que põe em cena esse relativismo em relação ao inferno e o paraíso: ao chegar no mais profundo do inferno, Dante passa pelo corpo de Lúcifer e lhe ocorre o é belamente descrito por Flávio Aguiar:

Para sair do inferno, Dante deve passar pelo corpo de Lúcifer, no vértice que ele descera em companhia de Virgílio. o poeta se apoia nos pêlos de Satã e desce até a virilha do gigante tricéfalo, que masca os três grandes traidores da humanidade: Cássio, Brutus e Judas. Passado esse ponto nevrálgico do mundo, do inferno, e do universo, ponto a que convergem as linhas do subterrâneo em que o poeta se perdera, Dante se dá conta de que não desce mais, mas sobe; voltando à rocha, contempla uma imagem nova do mundo satânico: o Mal personificado, Lúcifer, senhor do mundo subterrâneo e contedor dos desígnios divinos no terreno, está de cabeça pra baixo. Dante vê então o Demônio na sua verdadeira posição, de pernas para o ar, como fora jogado do céu depois de sua revolta contra Deus. Depois desta visão, nada mais há a ver no Inferno, pois a chave deste está decifrada. Dante e Virgílio se encaminham rapidamente à saída e esta parte do poema termina aos pés do Purgatório. (1998, p.317)

Assim, Dante nos apresenta um inferno que possui sua própria noção de alto e baixo, diferente da relação direta com o paraíso como altura absoluta. Lúcifer, ao cair do céu, fundou sua própria altitude e, em relação a este, é o paraíso que se encontra embaixo. Em sentido aproximado, na Divina Comédia de Gaiad, Paraíso e Inferno se tocam em intensidade e, desta maneira, o cair e voar da carne são apenas percurso possíveis de um mesmo movimento. 
Referências Bibliográficas

> AGUIAR, Flavio. Visões do inferno ou o retorno da aura. In: NOVAES, Adauto (et al). 0 Olhar. SP: Cia. das Letras, 1998.

> ALIGHIERI, Dante. A Divina Comédia. SP: Círculo do Livro.

> BATAILLE, Georges. 0 Erotismo. Porto Alegre: LCAPM, 1987.

> BAUDRILLARD, Jean. Da Sedução. SP: Papirus, 1991.

$>$ BRETON, André. Nadja. SP: Cosac Naify, 2007.

Priscilla Menezes de Faria, graduada em Licenciatura em Artes Plásticas pelo CEART - UDESC.

priscilla.menezes@gmail.com 